\title{
Erratum to: The reading performance of English learners in grades 1-3: the role of initial status and growth on reading fluency in Spanish and English
}

\author{
Doris Luft Baker $\cdot$ Yonghan Park $\cdot$ Scott K. Baker
}

Published online: 29 November 2011

(C) Springer Science+Business Media B.V. 2011

\section{Erratum to: Read Writ \\ DOI 10.1007/s11145-010-9261-z}

The original publication of the article includes an error in Table 4. The scores indicated in the table for third grade were incorrect. This mistake did not affect the overall results of the study. Only in the Discussion section under "Relations of reading fluency to reading comprehension within and across languages," the percentage of variance explained in English comprehension in third grade needs to be changed from $35 \%$ (95\% CI: $22-47 \%$ ) to $37 \%$ (95\% CI: $24-50 \%$ ).

The complete and correct version of Table 4 is given below:

The online version of the original article can be found under doi:10.1007/s11145-010-9261-z. 


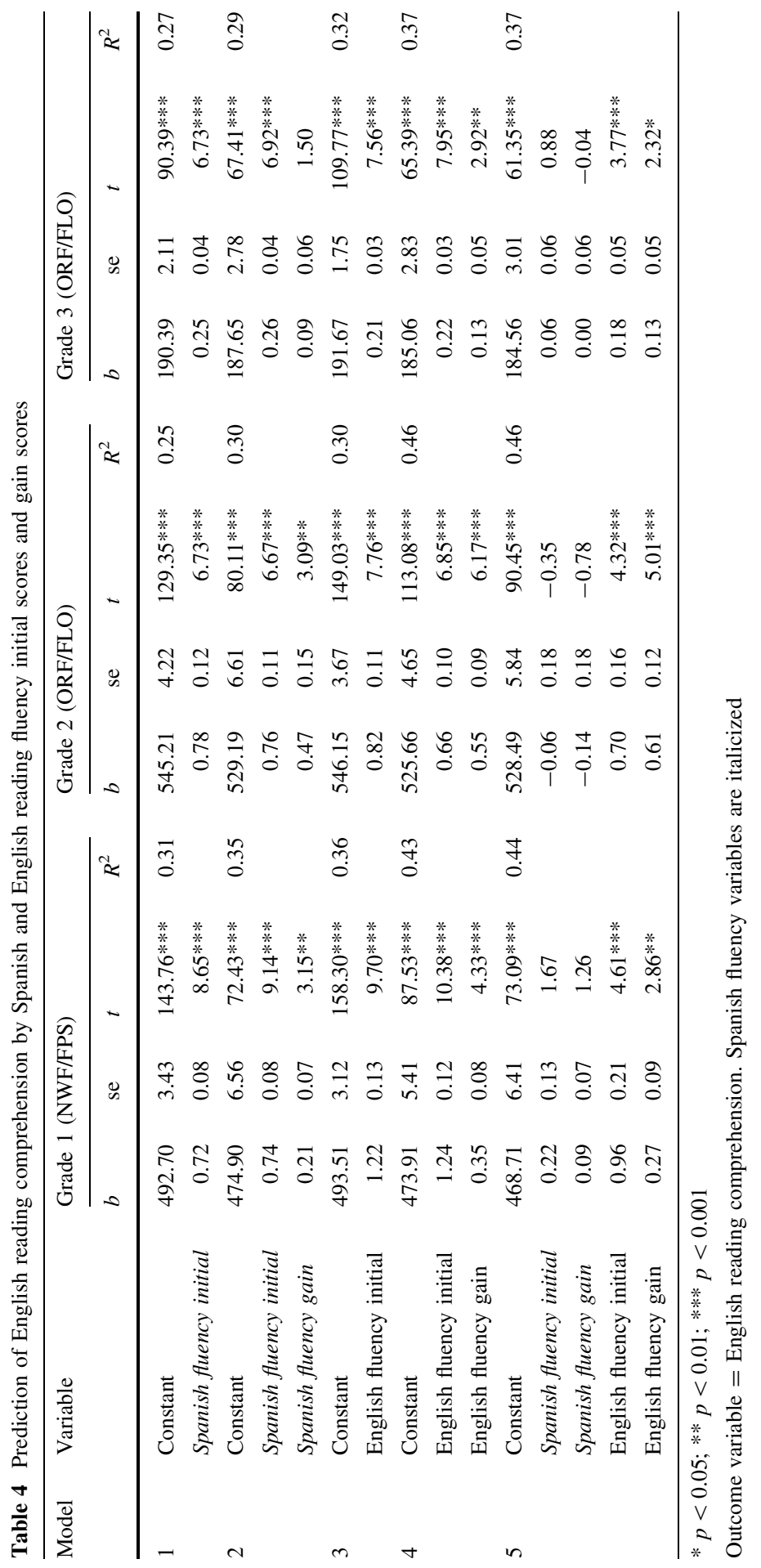

